\title{
Freqüência de enteroparasitas em amostras de alface (Lactuca sativa) comercializadas em Lavras, Minas Gerais
}

\author{
Frequency of intestinal parasites in samples of lettuce (Lactuca sativa) \\ commercialized in Lavras, Minas Gerais State

\begin{abstract}
Antônio Marcos Guimarães', Endrigo Gabellini Leonel Alves', Henrique César Pereira Figueiredo ${ }^{1}$, Geraldo Márcio da Costa ${ }^{1}$ e Luciano dos Santos Rodrigues ${ }^{2}$
\end{abstract}

Resumo O objetivo deste trabalho foi realizar uma avaliação parasitológica em amostras de alface (Lactuca sativa) comercializadas em Lavras, MG. As amostras de alfaces apresentaram baixos padrões higiênicos, indicados pela presença de formas parasitológicas de origem animal ou humana e alta concentração de coliformes fecais.

Palavras-chaves: Hortaliças. Alface. Parasitas intestinais. Coliformes fecais.

Abstract The aim of this study was to evaluate the parasitological contamination in samples of lettuce (Lactuca sativa) commercialized in Lavras city, Minas Gerais. The samples of lettuce showed low hygienic conditions, indicated by the presence of parasites of animal or human origin and high concentration of fecal coliforms.

Key-words: Vegetables. Lettuce. Intestinal parasites. Fecal coliform.

Estudos realizados no Brasil têm verificado a possibilidade de contaminação alimentar por helmintos e protozoários devido à ingestão de hortaliças consumidas cruas, provenientes de áreas cultivadas e contaminadas por dejetos fecais ${ }^{5}$.

Considerando a ausência de dados em Lavras, MG, este trabalho visou determinar a freqüência de enteroparasitas em amostras de alfaces comercializadas em supermercados, sacolões e feiras livres deste município. Neste experimento, utilizou-se 120 amostras de alface (Lactuca sativa), coletadas aleatoriamente de sacolões, feiras livres e supermercados de Lavras, no período de abril de 2001 a maio de 2002.

A pesquisa de enteroparasitas foi realizada após duas lavagens das verduras. Primeiramente, por enxaguadura, colocando $250 \mathrm{ml}$ de água destilada no saco plástico contendo a verdura e agitando-o manualmente. Na segunda lavagem, após desfolhamento de cada pé-de-alface, desprezandose as deterioradas, as folhas foram pinceladas, individualmente, em um pirex de vidro com $250 \mathrm{ml}$ da solução detergente neutro recém-preparada (IRGASAN ${ }^{\circledR}$ a $0,5 \%$ em água destilada). Em seguida, ambas soluções de lavagens foram deixadas em repouso em cálice cônico de sedimentação, coberto por placa de Petri, por 24 horas.

Após essas etapas, $0,1 \mathrm{ml}$ do sedimento obtido de ambas lavagens foi examinado em duplicata em microscópio óptico (10x e 40x). Posteriormente, aproximadamente $50 \mathrm{ml}$ de sedimentos, de ambas lavagens, foram divididos em tubos de $15 \mathrm{ml} e$ centrifugados a $2.500 \mathrm{rpm}$ durante um minuto, desprezando o sobrenadante. Uma parte do sedimento obtido foi ressuspendida em solução de Sheather e de sulfato de zinco a $33 \%$ e examinada em microscópio óptico (40x). Oocistos de Cryptosporidium sp e de Cyclospora cayetanensis foram pesquisados pelo método de Kinyoun modificado ${ }^{1}$. Na pesquisa de coproantígeno específico de Giardia lamblia (GSA 65), em 85 amostras de alfaces, utilizou-se o kit comercial ProSpecT Ensaio Imunoenzimático em microplaca (Alexon, Inc, BIOBRÁS).

\footnotetext{
1. Departamento de Medicina Veterinária da Universidade Federal de Lavras, Lavras, MG, Brasil. 2. Departamento de Medicina Veterinária Preventiva da Escola de Veterinária da Universidade Federal de Minas Gerais, Belo Horizonte, MG.

Endereço para correspondência: Prof. Antônio Marcos Guimarães. DMV/UFLA. Caixa Postal 37, 37200-000 Lavras, MG, Brasil.

Tel: 5535 3829-1708. Fax: 5535 3829-1715

e-mail: amg@ufla.br

Recebido para publicação em 10/9/2002

Aceito em 23/7/2003
} 
Para estimar a contaminação fecal em $50 \%$ das verduras $(n=60)$, foram coletados, em frascos estéreis, $50 \mathrm{ml}$ da água de lavagem de cada enxágüe, formando-se assim uma amostra composta de $100 \mathrm{ml}$ para cada ponto de comercialização. Foi determinado o número mais provável de bactérias dos grupos coliformes totais e coliformes fecais (NMP), segundo metodologia recomendada pela American Public Health Association ${ }^{2}$. O cálculo do NMP de coliformes fecais foi determinado com auxílio da tabela do NMP-série de três tubos ${ }^{3}$.

$\mathrm{Na}$ análise estatística foi utilizado o teste $\mathrm{t}$ de Student e o método de qui-quadrado ${ }^{9} \mathrm{com}$ nível de significância de 5\%.

Em todas as amostras de alfaces $(n=120)$, independente do tipo de estabelecimento comercial (sacolões, supermercado e feiras-livres), ocorreu algum tipo de contaminação. Em ordem decrescente, as formas parasitárias e/ou contaminantes mais freqüentes foram: larvas de nematódeos - 47,5\% (57/120); ovos de ácaros - 41,7\% (50/120); ácaros - 40,8\% (49/ $120)$; insetos - $34,2 \%(41 / 120)$; ovos de outros nematódeos - 30,8\% (37/120); oocistos não esporulados - 23,3\% (28/120), ovos tipo estrongilóide - 21,7\% (26/120); cistos de Entamoeba sp - 5\% (6/120) e ovos de Toxocara sp - 1,7\% (2/120). Os resultados obtidos para cada tipo de estabelecimento constam na Tabela 1. A contaminação por formas parasitárias não apresentou diferença significativa $(p>0,05)$ pelo teste de qui-quadrado entre as amostras comercializadas em supermercados, sacolões ou feiras-livres.

Quando se compara o resultado obtido neste trabalho com os de outros estudos realizados no Brasil,

Tabela 1- Freqüência de formas parasitarias em amostras de alface $(n=120)$ comercializadas em diferentes tipos de estabelecimentos comerciais de Lavras, MG, no período de abril de 2001 a maio de 2002.

\begin{tabular}{|c|c|c|c|c|c|c|}
\hline \multirow{2}{*}{$\begin{array}{l}\text { Formas } \\
\text { parasitárias }\end{array}$} & \multicolumn{2}{|c|}{$\begin{array}{c}\text { Supermercados }(n=40) \\
\text { positivos }\end{array}$} & \multicolumn{2}{|c|}{$\begin{array}{c}\text { Sacolões }(n=40) \\
\text { positivos }\end{array}$} & \multicolumn{2}{|c|}{$\begin{array}{c}\text { Feiras-livres }(n=40) \\
\text { positivos }\end{array}$} \\
\hline & $n^{\circ}$ & $\%$ & $\mathrm{n}^{\circ}$ & $\%$ & $\mathrm{n}^{\circ}$ & $\%$ \\
\hline Insetos & 15 & 37,5 & 11 & 27,5 & 15 & 37,5 \\
\hline Ácaros & 15 & 37,5 & 16 & 40 & 17 & 42,5 \\
\hline Ovos de ácaros & 16 & 40,0 & 16 & 40 & 18 & 45,0 \\
\hline Ovos tipo estrongilóide & 3 & 7,5 & 8 & 20,0 & 15 & 37,5 \\
\hline Ovos de Toxocara sp & 1 & 2,5 & 1 & 2,5 & 0 & 0,0 \\
\hline Ovos de outros nematódeos & 14 & 35,0 & 9 & 22,5 & 14 & 35,0 \\
\hline Larvas de nematódeos & 17 & 42,5 & 20 & 50,0 & 20 & 50,0 \\
\hline Oocistos não esporulados & 9 & 22,5 & 7 & 17,5 & 12 & 30,0 \\
\hline Cistos de Entamoeba sp & 1 & 2,5 & 3 & 7,5 & 2 & 5,0 \\
\hline
\end{tabular}

observa-se uma grande variação no tipo ou freqüência de enteroparasitas, explicada, em parte, pela localidade, tipos de hortaliças e metodologia utilizada no exame parasitológico. No entanto, independente de sua freqüência, parasitas intestinais presentes em hortaliças comercializadas no município de Lavras não diferiram substancialmente de descritos em outros estudos ${ }^{510}$. Embora em baixo nível, a presença de ovos de Toxocara sp. sugere contaminação por fezes de cães e/ou gatos.

Oocistos de Cryptosporidium sp e/ou de Cyclospora cayetanensis e coproantígenos específicos de G. lamblia não foram identificados em nenhuma das amostras de alface examinadas. Apesar do ensaio imunoenzimático apresentar uma alta sensibilidade e especificidade na detecção de coproantígeno de G. lamblia em amostras fecais ${ }^{7}$, provavelmente devido à metodologia empregada, não se atingiu o mesmo resultado testando amostras de alface.

No exame microbiológico, todas amostras de alface apresentaram alta contagem de coliformes totais e fecais (coliformes em NMP por 100ml de água). A contagem média global de coliformes fecais para cada tipo de estabelecimento comercial, em ordem decrescente, foi: feiras-livres $\left(8,6 \times 10^{5}\right)$, sacolões $\left(3,8 \times 10^{5}\right)$ e supermercados $\left(3,2 \times 10^{5}\right)$. A análise de variância apresentou uma variação significativa $(p<0,01)$ no grau de contaminação por coliformes fecais entre os pontos de vendas. No entanto, apenas 15,3\% dessa variação se devem ao tipo de estabelecimento comercial; os outros $84,7 \%$ devem-se a outros fatores que não o ponto de venda das hortaliças.

No Brasil, embora escassos, estudos têm constatado verduras com alto grau de contaminação por coliformes fecais ${ }^{10}$. A água utilizada na irrigação constitui importante fonte de contaminação para hortaliças ${ }^{6}{ }^{10}$. Em Lavras, análises bacteriológicas de 81 amostras de água, de 44 propriedades rurais, utilizada, entre outras finalidades, na irrigação de lavouras, demonstraram que quase a totalidade dos mananciais apresentava contaminação por coliformes fecais ${ }^{8}$. Esse resultado poderia justificar, em parte, a alta contagem de coliformes fecais em amostras de alfaces comercializadas no município. Por outro lado, demonstra que, em algum momento, seja na produção, transporte, armazenagem ou manipulação das hortaliças, houve contato dessas verduras com fezes de seres humanos e/ou de animais. 
Nas condições em que foi desenvolvido este estudo conclui-se que, as amostras de alfaces comercializadas em supermercados, sacolões e feiras livres de Lavras,
MG, apresentam baixo padrão higiênico, evidenciado pela presença de formas parasitárias de origem humana e/ou animal e alta contaminação por coliformes fecais.

\section{REFERÊNCIAS BIBLIOGRÁFICAS}

1. Amato Neto V, Braz LMA, Pietro AOD. Pesquisa de oocistos de Cryptosporidium sp em fezes: comparação entre métodos de Kinyoun modificado e de Heine. Revista da Sociedade Brasileira de Medicina Tropical 29: 575-578, 1996.

2. American Public Health Association. Technical Committee on Microbiological Methods for Foods. In: Vanderzant C, Splittstoesser DF (eds) Compendium of methods for the microbiological examination of foods. $3^{\text {rd }}$ edition, American Health Association, Washington, p. 336-383, 1992.

3. Carvalho EP. Microbiologia de alimentos. Universidade Federal de Lavras: Departamento de Ciências de Alimentos, 1995.

4. Marzochi MCA. Estudo dos fatores envolvidos na disseminação dos enteroparasitas. II- Estudo da contaminação de verduras e solo de hortas na cidade de Ribeirão Preto, São Paulo, Brasil. Revista do Instituto de Medicina Tropical de São Paulo 19: 148156, 1997.

5. Mesquita VCL, Serra MB, Bastos OMP, Uchôa CMA. Contaminação por enteroparasitas em hortaliças comercializadas nas cidades de Niterói e Rio de Janeiro, Brasil. Revista da Sociedade Brasileira de Medicina Tropical 32: 363-366, 1999.

6. Oliveira CAF, Germano PML. Estudo da ocorrência de enteroparasitas em hortaliças comercializadas na Região
Metropolitana de São Paulo - SP, Brasil. I - Pesquisa de helmintos. Revista de Saúde Pública 26: 283-289, 1992a.

7. Rocha MO, Mello RT, Guimarães TMPD, Toledo VPCP, Moreira MCCG, Costa CA. Detection of a Giardia lamblia coproantigen by using a commercially available immunoenzymatic assay, in Belo Horizonte, Brazil. Revista Instituto Medicina Tropical de São Paulo 41: 151-154, 1999.

8. Rocha CMBM, Rodrigues LS, Costa CC, Oliveira PR, Silva IJ, De Jesus EF, Gomes E. Avaliação da relação entre os tipos de mananciais e a qualidade de água utilizada na zona rural do município de Lavras/MG. In: Resumos do V Congresso Brasileiro de Epidemiologia, Curitiba, PR, p. 458, 2002.

9. Sampaio IB. Estatística Aplicada à Experimentação Animal. Fundação de Ensino e Pesquisa em Medicina Veterinária e Zootecnia. Belo Horizonte, 1988.

10. Takayanagui OM, Oliveira CD, Bergamini AMM, Capuano DM, Okino MHT, Febrônio LHP, Silva AAMCC, Oliveira MA, Ribeiro EGA, Takayanagui AMM. Fiscalização de verduras comercializadas no município de Ribeirão Preto, SP. Revista da Sociedade Brasileira de Medicina Tropical 34: 37-41, 2001. 